\title{
Perdas de silagens de cana-de-açúcar tratadas com aditivos químicos e bacterianos
}

\author{
Gustavo Rezende Siqueira ${ }^{1,2}$, Ricardo Andrade Reis ${ }^{3}$, Ruben Pablo Schocken-Iturrino ${ }^{4}$, \\ Aureliano José Vieira Pires ${ }^{5}$, Thiago Fernandes Bernardes ${ }^{6}$, Rafael Camargo do Amaral ${ }^{7}$ \\ ${ }^{1}$ APTA - Pólo Regional de Desenvolvimento Tecnológico dos Agronegócios da Alta Mogiana - Av. Rui Barbosa, s/nº, C.P. 35, CEP: 14.770-000 \\ Colina, SP. \\ 2 Doutoramento em Zootecnia da FCAVIUNESP, Campus de Jaboticabal. \\ ${ }^{3}$ Dep. de Zootecnia da FCAVIUNESP, Campus de Jaboticabal. Bolsista do CNPq. \\ ${ }^{4}$ Dep. de Microbiologia da FCAVIUNESP, Campus de Jaboticabal. Bolsista do CNPq \\ ${ }^{5}$ DTRA/UESB, Campus de Itapetinga. Bolsista do CNPq. \\ ${ }^{6}$ Pós-doutorando - ESALq/USP - Bolsista FAPESP. \\ 7 Mestrando em Ciência Animal e Pastagem, ESALQ/USP.
}

RESUMO - Objetivou-se avaliar silagens de cana-de-açúcar tratadas com aditivos químicos (uréia 1,5\%; benzoato de sódio $0,1 \%$; ou hidróxido de sódio $(\mathrm{NaOH}) 1 \%$ na matéria natural) combinados ou não com inoculantes (Propionibacterium acidipropionici + Lactobacillus plantarum ou Lactobacillus buchneri). Foram avaliadas 12 silagens: uma controle, sem inoculante e sem aditivo químico; três sem inoculante, mas com um dos aditivos; uma com P. acidipropionici + L. plantarum, sem aditivo químico; três com P. acidipropionici $+L$. plantarum e um dos aditivos; uma com $L$. buchneri, sem aditivo químico; e três com $L$. buchneri e um dos aditivos. Os dados foram analisados em esquema fatorial $4 \times 3$ com três repetições para cada tratamento. Foram determinadas as perdas ocorridas durante o processo fermentativo nas formas de gases e de efluentes e a recuperação da MS. Durante a exposição aeróbia, determinaram-se a recuperação da MS e a estabilidade aeróbia medida pela variação da temperatura. A associação de L. buchneri e $\mathrm{NaOH}$ reduziu as perdas por gases e efluentes e elevou a recuperação da MS. No período após abertura, destacou-se a atuação do benzoato de sódio em manter o pH com variação de apenas 0,1 unidade em cinco dias de exposição aeróbia e dos inoculantes L. buchneri e P. acidipropionici + L. plantarum em prolongar o tempo para elevação da temperatura de 34 horas nas silagens controle para 54 e 50 horas, respectivamente. A ensilagem de cana-de-açúcar requer a inclusão de algum aditivo eficiente no controle das perdas quantitativas durante a fermentação e a exposição aeróbia.

Palavras-chave: estabilidade aeróbia, fermentação, inoculantes, silagem, valor nutritivo

\section{Losses evaluation of the sugar cane silage treated with chemical and microbial additives}

\begin{abstract}
The experiment was carried out to evaluate sugar cane silage treated with chemical additive: urea $1.5 \%$, sodium benzoate $0.1 \%$, and sodium hydroxide $1.0 \%$ on the wet basis, associated with Propionibacterium acidipropionici + Lactobacillus plantarum and Lactobacillus buchneri, plus control silage in a factorial scheme $4 \times 3$, with three replications The gas and effluents losses during the fermentation phase, and dry matter recovery were determined. During the aerobic phase were determined the dry matter recovery and aerobic stability through the temperature variation. The Lactobacillus buchneri and $\mathrm{NaOH}$ association reduced gas and effluent losses and increased the dry matter recovery. At the aerobic phase, the sodium benzoate maintained the $\mathrm{pH}$ values, with changes of 0.1 unit during five days. The time to temperature elevation increased from 34 hours on the control silage to 54.0 and 50.0 hours, respectively on the silage inoculated with Propionibacterium acidipropionici + Lactobacillus plantarum or Lactobacillus buchneri. The sugar cane silage production required an efficient additive inclusion which can control the quantitative losses during the fermentation and aerobic phases.
\end{abstract}

Key Words: aerobic stability, fermentation, inoculants, nutritive value, silage

\section{Introdução}

A ensilagem da cana-de-açúcar é uma prática crescente no Brasil e que não tem sido pesquisada quanto às perdas durante o processo fermentativo. Verifica-se, no entanto, a necessidade de utilização de aditivos que efetivamente controlem a produção de etanol para o sucesso na ensilagem dessa forrageira (Nussio et al., 2003). Jobim \& Gonçalves (2003) alertaram para o efeito da entrada de ar na massa ensilada, uma vez que o oxigênio propicia a atuação de 
microrganismos deterioradores e a redução de açúcares solúveis e ácidos orgânicos, o que resulta em aumento de pH e redução na digestibilidade e no conteúdo de energia. Conseqüentemente, as silagens deterioradas podem conduzir a perdas econômicas elevadas e baixo desempenho animal.

Além da produção de etanol, a fermentação por leveduras gera água, ATP e produção de $\mathrm{CO}_{2}$, que é bastante significativa. Na ensilagem da cana-de-açúcar perdas por gases têm muita importância, pois são altamente correlacionadas ao teor de etanol $(90,3 \%)$ e à recuperação de MS (89,3\%) (Pedroso et al., 2005). Segundo McDonald et al. (1991), a fermentação por leveduras ocasiona perdas de $48,9 \%$ da MS.

Além das perdas durante a fermentação, segundo Siqueira et al. (2005), quando as silagens são expostas ao ar, microrganismos oportunistas iniciam atividade metabólica produzindo calor e consumindo nutrientes, de modo que alguns produtos da fermentação passam a ser substrato; microrganismos outrora latentes podem se desenvolver. Nesse sentido, o desabastecimento do silo e o fornecimento da silagem aos animais se revelam como um importante dreno de MS e energia durante o processo de ensilagem.

Com o objetivo de controlar perdas na ensilagem, diversos aditivos têm sido avaliados, entre eles, a uréia (Alvarez \& Preston, 1976), o hidróxido de sódio ( $\mathrm{NaOH}$ ) (Alcántara et al., 1989), o benzoato de sódio (Warth, 1988), o Propionibacterium (Flores-Galarza et al., 1985) e o Lactobacillus buchneri (Ranjit \& Kung Jr., 2000). Todavia, em um cenário de perdas durante a fermentação e estabilidade aeróbia, a associação de aditivos também tem sido alvo de estudos (Pölönen et al., 1998; Winters et al., 2001).

Neste trabalho objetivou-se avaliar silagens de canade-açúcar tratadas com aditivos químicos (uréia, benzoato de sódio e $\mathrm{NaOH}$ ) associados ou não a inoculantes bacterianos (P. acidipropionici + Lactobacillus plantarum e L. buchneri).

\section{Material e Métodos}

A cana-de-açúcar (Saccharum officinarum L.) utilizada foi o cultivar SP70-1143, proveniente da Usina Andrade Açúcar e Álcool, de Pitangueiras, distrito de Ibitiuva-SP. A colheita manual foi realizada no mês de outubro de 2003 quando a cana-de-açúcar estava apta para o quarto corte, com produção de matéria verde (MV) estimada de 80 t/ha aos 15 meses de crescimento vegetativo, com $16 \%$ de pol (\% sacarose da cana-de-açúcar) e teor médio de MS de 35,3\%.

Utilizou-se delineamento experimental inteiramente casualizado em esquema fatorial $3 \times 4$, com três repeti- ções, composto dos fatores inoculação (controle, $P$. acidipropionici $+L$. plantarum e $L$. buchneri) e aditivos químicos (controle, uréia, benzoato de sódio e hidróxido de sódio).

A cana-de-açúcar foi transportada até as dependências da UNESP, Campus de Jaboticabal, e no dia posterior ao corte foi picada em máquina estacionária em partículas de 1 a $3 \mathrm{~cm}$, sem sofrer despalhamento.

Foram avaliadas 12 silagens: uma controle, sem inoculante e sem aditivo químico; três sem inoculante, mas com $1,5 \%$ de uréia, $0,1 \%$ de benzoato de sódio ou $1 \%$ de hidróxido de sódio; uma com $P$. acidipropionici + L. plantarum, sem aditivo químico; três com $P$. acidipropionici $+L$. plantarum e aditivo químico $(1,5 \%$ de uréia; 0,1\% de benzoato de sódio; ou 1\% de hidróxido de sódio); uma com L. buchneri, sem aditivo químico; e três com $L$. buchneri e aditivo (1,5\% de uréia, $0,1 \%$ de benzoato de sódio ou 1\% de hidróxido de sódio).

Os microrganismos Propionibacterium acidipropionici (Cepa MS 01) e Lactobacillus plantarum (Cepa MA 18/50) são encontrados no inoculante comercial Propiolact ${ }^{\circledR}$ (PROP) e o microrganismo Lactobacillus buchneri (Cepa NCIMB 40788) é encontrado no inoculante comercial LalsilCana ${ }^{\circledR}$ (BUCH). O P. acidipropionici e o $L$. plantarum foram aplicados na dose de $1,5 \times 10^{5} \mathrm{ufc} / \mathrm{g}$ de forragem e o L. buchneri na dose de $5 \times 10^{4} \mathrm{ufc} / \mathrm{g}$ de forragem. A uréia foi diluída em água e aplicada em solução de $35 \mathrm{~L} / \mathrm{t}$ de forragem, o benzoato de sódio foi aplicado por meio de solução de $15 \mathrm{~L} / \mathrm{t}$ e o hidróxido de sódio $(\mathrm{NaOH})$ foi utilizado em solução de $33,3 \%$ aplicando-se $30 \mathrm{~L} / \mathrm{t}$. Nas silagens com inoculante e aditivo químico, a aplicação foi realizada separadamente, pulverizando-se primeiramente o inoculante e logo após o aditivo químico.

Como silos experimentais foram utilizados tubos de PVC de $50 \mathrm{~cm}$ de altura e $10 \mathrm{~cm}$ de diâmetro, com tampas com válvulas de Bunsen para permitir o escape dos gases. No fundo dos silos, colocou-se areia seca $(1,2 \mathrm{~kg})$ separada da forragem por uma tela e um tecido de náilon para quantificação do efluente produzido.

A compactação do material picado foi realizada com bastões de ferro objetivando atingir densidade de $650 \mathrm{~kg} / \mathrm{m}^{3}$ de forragem. Determinou-se o volume de cada silo experimental, descontando-se o espaço ocupado pela areia e pesou-se a quantidade de forragem necessária para obtenção da densidade desejada. Após a compactação da forragem, os silos foram vedados com fita adesiva, pesados e armazenados. Aos 60 dias de fermentação, foram novamente pesados para determinação das perdas por gases e, em seguida, foram abertos. 
Após a retirada da silagem, o conjunto silo, areia, tela e tecido de náilon foi pesado para quantificação do efluente produzido. A determinação da perda gasosa foi calculada pela fórmula:

$$
\mathrm{PG}=(\mathrm{PSI}-\mathrm{PSF}) / \mathrm{MSI} \times 100 \text {, }
$$

em que: $\mathrm{PG}=$ perda por gases $(\%$ da MS); $\mathrm{PSI}$ = peso do silo no momento da ensilagem $(\mathrm{kg}), \mathrm{PSF}=$ peso do silo no momento da abertura (kg); e MSI = matéria seca ensilada (quantidade de forragem em $\mathrm{kg} \times \% \mathrm{MS}$ )

A determinação da produção de efluente foi calculada pela equação:

$$
\mathrm{PE}=(\mathrm{PSAF}-\mathrm{PSAI}) / \mathrm{MNI} \times 1000 \text {, }
$$

em que: $\mathrm{PE}=$ produção de efluente $(\mathrm{kg}$ de efluente/t de matéria verde ensilada); PSAF = peso do conjunto silo, areia, tela e náilon após a abertura (kg); PSAI = peso do conjunto silo, areia, tela e náilon antes da ensilagem (kg); e MNI = quantidade de forragem ensilada $(\mathrm{kg})$.

Recuperação de MS: $\left(\mathrm{MS}_{\mathrm{i}} / \mathrm{MS}_{\mathrm{f}}\right) * 100$, em que: $\mathrm{MS}_{\mathrm{f}}=$ quantidade de $\mathrm{MS}$ final; $\mathrm{MS}_{\mathrm{i}}=$ quantidade de MS inicial.

A variação dos teores de MS foi calculada como a diferença em módulo da porcentagem de MS no momento da ensilagem e da porcentagem de MS na abertura.

Antes da ensilagem, após a aplicação dos inoculantes e/ou aditivos, a forragem foi amostrada três vezes para cada tratamento. Cada amostra foi fragmentada em duas subamostras: uma foi utilizada para determinação da capacidade tampão, segundo metodologia descrita por Playne \& McDonald (1966), e do pH, segundo Silva \& Queiroz (2002); e a outra foi pesada e levada para estufa de ventilação forçada a $55^{\circ} \mathrm{C}$ durante 72 horas.

Na abertura dos silos, após homogeneização da silagem, foram retiradas duas amostras de cada silo. Uma das amostras coletadas foi preparada segundo metodologia descrita por Kung Jr. et al. (1984) para determinação do pH em potenciômetro (Silva \& Queiroz, 2002) e do nitrogênio amoniacal em relação ao nitrogênio total $\left(\mathrm{N}-\mathrm{NH}_{3}\right)$ (Chaney \& Marbach, 1962). A outra amostra foi pesada e mantida em estufa de ventilação forçada a $55^{\circ} \mathrm{C}$ durante 72 horas. As amostras mantidas em estufa colhidas antes da ensilagem e após a abertura dos silos, foram novamente pesadas, trituradas em moinho de faca até obtenção de partículas com menos de 1 mm e armazenadas em potes de plástico para determinação da MS conforme metodologia descrita por Silva \& Queiroz (2002).

Após a abertura dos silos, amostras foram colocadas em baldes plásticos, pesadas e armazenadas em câmara climática a $25 \pm 1^{\circ} \mathrm{C}$ para avaliação da estabilidade aeróbia. As temperaturas das silagens no período após abertura foram obtidas a cada 12 horas durante cinco dias por meio de um termômetro inserido na massa de silagem contida nos baldes. A estabilidade aeróbia foi calculada como o tempo gasto, em horas, para a massa de forragem elevar em $1^{\circ} \mathrm{C} \mathrm{em}$ relação à temperatura do ambiente (Driehuis et al., 2001). Decorridos cinco dias de exposição aeróbia, os baldes com as amostras foram novamente pesados para determinação da recuperação da MS e as silagens foram amostradas para determinação da MS.

Os dados foram analisados estatisticamente pelos procedimentos da análise de variância e as médias comparadas pelo teste Tukey a 5\% de significância utilizando-se o programa de Análise Estatística ESTAT 2.0, 1994 - Unesp.

\section{Resultados e Discussão}

A capacidade tampão representa a resistência de determinada substância em alterar o pH. Na ensilagem deseja-se que a forragem apresente baixa capacidade tampão, pois isso facilita a redução do $\mathrm{pH}$, em virtude da produção de ácidos orgânicos durante o processo de fermentação. Independentemente da inoculação, os maiores valores de capacidade tampão foram obtidos nas forragens tratadas com $\mathrm{NaOH}(\mathrm{P}<0,05)$ (Tabela 1$)$, uma vez que esse aditivo em solução aquosa dissocia-se no íon sódio $\left(\mathrm{Na}^{+}\right)$e em hidroxila $\left(\mathrm{OH}^{-}\right)$, que tem a capacidade de combinar com o $\mathrm{H}^{+}$do meio e inibir as alterações do $\mathrm{pH}$.

À exceção das silagens tratadas com $\mathrm{NaOH}$, os valores de capacidade tampão obtidos nas silagens foram um pouco inferiores aos encontrados por Bernardes et al. (2007), que avaliaram a ensilagem de cana-de-açúcar e observaram capacidade tampão de 9,2 e.mg de HCl/100 g de MS. Vários fatores podem afetar a capacidade tampão, entre eles, os teores de carboidratos solúveis, de nitrogênio e de minerais. Ao contrário do previsto, a uréia não elevou a capacidade tampão da forragem, provavelmente porque a transformação da uréia em hidróxido de amônia é um processo lento e a forma de hidróxido de amônia é capaz de elevar a capacidade tampão.

Independentemente da inoculação, as silagens tratadas com uréia apresentaram maiores teores de $\mathrm{N}-\mathrm{NH}_{3}$ $(\mathrm{P}<0,05)$ (Tabela 1). Ao ser hidrolisada pela urease, a uréia transforma-se em $\mathrm{NH}_{3}$, que reage com água produzindo hidróxido de amônia (Sundstol \& Coxworth, 1984), elevando o teor de $\mathrm{N}-\mathrm{NH}_{3}$. Essa reação parece a princípio indesejável, porém, na ensilagem de cana-de-açúcar a presença de amônia pode consistir em vantagem, em virtude do controle de leveduras. Além disso, os valores de $\mathrm{N}^{-\mathrm{NH}_{3}}$ foram maiores nas silagens tratadas com $L$. buchneri $(74,5 \%)$ em associação à uréia, seguidas das silagens tratadas com P. acidipropionici + L. plantarum (56,6\%). Provavelmente, 
Tabela 1 - Capacidade tampão da forragem antes da ensilagem e teores de nitrogênio amoniacal em relação ao nitrogênio total na MS $\left(\mathrm{NH}_{3}\right)$ de silagens de cana-de-açúcar tratadas com aditivos químicos e bacterianos

Table 1 - Sugar cane buffer capacity (BC), sugar cane silage ammonia nitrogen in relation to total $\left.\mathrm{N}_{(\mathrm{NH}}\right)$ in function of the chemical and bacterial additive association

\begin{tabular}{|c|c|c|c|c|c|c|c|c|}
\hline \multirow[t]{2}{*}{$\begin{array}{l}\text { Tratament } \\
\text { Treatment }\end{array}$} & \multicolumn{4}{|c|}{$\begin{array}{l}\text { Capacidade tampão (e.mg de } \mathrm{HCl} / 100 \mathrm{~g} \text { de } \mathrm{MS})^{2} \\
\qquad B C(\text { e.mg of } H C l / 100 \mathrm{~g} \text { of } D M)\end{array}$} & \multicolumn{4}{|c|}{$\begin{array}{c}\mathrm{N}-\mathrm{NH}_{3}(\% \text { do } \mathrm{N} \text { total }) \\
\mathrm{N} \text { ammonia }(\% \text { Total } \mathrm{N})\end{array}$} \\
\hline & $\begin{array}{c}\text { Controle } \\
\text { Control }\end{array}$ & $\begin{array}{c}\text { Propionibacterium } \\
\text { acidipropionici }+ \\
\text { Lactobacillus plantarum }\end{array}$ & $\begin{array}{l}\text { Lactobacillus } \\
\text { buchneri }\end{array}$ & $\begin{array}{l}\text { Média } \\
\text { Mean }\end{array}$ & $\begin{array}{c}\text { Controle } \\
\text { Control }\end{array}$ & $\begin{array}{c}\text { Propionibacterium } \\
\text { acidipropionici }+ \\
\text { Lactobacillus plantarum }\end{array}$ & $\begin{array}{l}\text { Lactobacillus } \\
\text { buchneri }\end{array}$ & $\begin{array}{l}\text { Média } \\
\text { Mean }\end{array}$ \\
\hline $\begin{array}{l}\text { Controle } \\
\text { Control }\end{array}$ & $7,0 \mathrm{Ab}$ & $5,64 \mathrm{Ab}$ & $6,2 \mathrm{Ab}$ & $6,3 b$ & $2,9 \mathrm{Ab}$ & $4,0 \mathrm{Ab}$ & $4,8 \mathrm{Ab}$ & $3,9 b$ \\
\hline $\begin{array}{l}\text { Benzoato } \\
\text { Benzoate }\end{array}$ & $7,4 \mathrm{Ab}$ & $7,21 \mathrm{Ab}$ & $6,5 \mathrm{Ab}$ & $7,0 \mathrm{~b}$ & $4,6 \mathrm{Ab}$ & $4,8 \mathrm{Ab}$ & $5,2 \mathrm{Ab}$ & $4,9 b$ \\
\hline $\begin{array}{l}\mathrm{NaOH} \\
\text { Média } \\
\text { Mean }\end{array}$ & $\begin{array}{r}35,5 \mathrm{Aa} \\
14,0 \mathrm{~A}\end{array}$ & $\begin{array}{r}34,81 \mathrm{Aa} \\
13,7 \mathrm{~A}\end{array}$ & $\begin{array}{r}28,2 \mathrm{Ba} \\
11,4 \mathrm{~B}\end{array}$ & $\begin{array}{r}32,8 \mathrm{a} \\
11,5\end{array}$ & $\begin{array}{r}3,3 \mathrm{Ab} \\
6,4 \mathrm{C}\end{array}$ & $\begin{array}{l}4,9 \mathrm{Ab} \\
17,6 \mathrm{~B}\end{array}$ & $\begin{array}{l}3,5 \mathrm{Ab} \\
22,0 \mathrm{~A}\end{array}$ & $\begin{array}{l}3,9 b \\
15,3\end{array}$ \\
\hline CV (\%) & & & 9,93 & & & & & 15,50 \\
\hline
\end{tabular}

Médias seguidas de mesma letra, maiúscula na linha e minúscula na coluna, não diferem estatisticamente pelo teste Tukey ( $\mathrm{P}>0,05)$.

1 1,5\% de uréia; $0,1 \%$ de benzoato de sódio e $1 \%$ de hidróxido de sódio em relação à matéria verde.

2 Equivalentes miligrama de ácido clorídrico por $100 \mathrm{~g}$ de MS.

Means followed by the same small letter within a column or capital letter in a row are similar $(P>0.05)$ by Tukey test.

1 Urea $1.5 \%$; sodium benzoate $0.1 \%$ and sodium hydroxide $1.0 \%$ on the wet basis.

2 Equivalent milligram of hydrochloric acid per $100 \mathrm{~g}$ of DM.

a eficiência de transformação de uréia em amônia nessas silagens foi maior, em razão da possível presença de urease de origem microbiana.

Antes da ensilagem, as forragens sem inoculantes tiveram maiores valores de $\mathrm{pH}$ (Tabela 2), que diferiram estatisticamente $(\mathrm{P}<0,05)$, porém, biologicamente essa diferença $(0,1$ unidade de $\mathrm{pH})$ pode ser considerada insignificante. No entanto, as forragens tratadas com $\mathrm{NaOH}$ apresentaram pH superior às demais, uma vez que o $\mathrm{NaOH}$ é considerado uma substância alcalinizante.

Após a abertura, as silagens tratadas com uréia sem inoculação e inoculadas com $P$. acidipropionici + L. plantarum apresentaram $\mathrm{pH}$ inferior ao daquelas tratadas com $\mathrm{NaOH}$ e superior ao das demais. As silagens inoculadas com L. buchneri, no entanto, não diferiram das tratadas com uréia e $\mathrm{NaOH}$, o que pode ser atribuído ao aumento da concentração de amônia nessas silagens, comprovado pelos valores de $\mathrm{N}-\mathrm{NH}_{3}$. Kung Jr. et al. (2003), em revisão sobre aditivos para ensilagem, concluíram que silagens tratadas com uréia e com eficiente transformação dessa uréia em amônia apresentam $\mathrm{pH}$ superior ao de silagens não tratadas. Considerando os valores de capacidade tampão, não se esperava obter $\mathrm{pH}$ elevado nas silagens tratadas com uréia, porém, a transformação da uréia em hidróxido de amônio, uma substância alcalinizante, não é um processo instantâneo. Segundo Lessard et al. (1978), a urease na ensilagem de milho foi capaz de hidrolisar $6 \mu \mathrm{mol}$ de uréia/g de MS/hora e manter essa taxa nos dois primeiros dias de ensilagem.
O tratamento da cana-de-açúcar com $\mathrm{NaOH}$ resultou em silagens com pH superior (Tabela 2). Em silagens com alta capacidade tampão, a quantidade de moles de ácido lático necessários para reduzir o pH em uma unidade é muito maior que em silagens com baixa capacidade tampão. Além disso, os ácidos orgânicos produzidos durante a fermentação geralmente se encontram dissociados elevando a capacidade tampão. Evangelista et al. (2003) observaram que à medida que aumentou o tempo de estocagem, a capacidade tampão das silagens elevou de 1,2 no dia da ensilagem para 17 e.mg de $\mathrm{HCl} / 100$ g de MS aos 60 dias de fermentação, comprovando que a cada dia de fermentação a redução do pH se torna mais difícil.

Entre as silagens tratadas com aditivos químicos (Tabela 3), aquelas com $\mathrm{NaOH}$ tiveram as menores perdas por gases, porém, não diferiram $(\mathrm{P}>0,05)$ daquelas tratadas com benzoato, sem inoculante, e com L. buchneri. A inoculação com $L$. buchneri resultou em menores perdas por gases nas silagens sem aditivos químicos e naquelas tratadas com benzoato.

O efeito sinérgico entre o aditivo químico $\mathrm{NaOH}$ e os inoculantes foi comprovado neste estudo, pois seu efeito combinado foi superior aos efeitos isolados. O efeito de $P$. acidipropionici + L. plantarum foi positivo somente em associação a $\mathrm{NaOH}$, o que parece estar associado ao $\mathrm{pH}$, pois a bactéria $P$. acidipropionici tem seu crescimento inibido em pH inferior a 4,5 (Higginbotham et al., 1998). O ácido propiônico tem efeito inibitório sobre o metabolismo de leveduras (Moon, 1983), contudo, Higginbotham et al. 
Tabela 2 - Valores de pH de silagens de cana-de-açúcar antes da ensilagem e após a abertura dos silos Table 2 - Sugar cane $\mathrm{pH}$ values before ensilage and after silo opening

\begin{tabular}{|c|c|c|c|c|c|c|c|c|}
\hline \multirow[t]{2}{*}{$\begin{array}{l}\text { Tratament } \\
\text { Treatment }\end{array}$} & \multicolumn{4}{|c|}{$\begin{array}{l}\text { Ensilagem } \\
\text { Ensilage }\end{array}$} & \multicolumn{4}{|c|}{$\begin{array}{l}\text { Abertura } \\
\text { Silo opening }\end{array}$} \\
\hline & $\begin{array}{l}\text { Controle } \\
\text { Control }\end{array}$ & $\begin{array}{c}\text { Propionibacterium } \\
\text { acidipropionici }+ \\
\text { Lactobacillus plantarum }\end{array}$ & $\begin{array}{l}\text { Lactobacillus } \\
\text { buchneri }\end{array}$ & $\begin{array}{l}\text { Média } \\
\text { Mean }\end{array}$ & $\begin{array}{c}\text { Controle } \\
\text { Control }\end{array}$ & $\begin{array}{c}\text { Propionibacterium } \\
\text { acidipropionici }+ \\
\text { Lactobacillus plantarum }\end{array}$ & $\begin{array}{l}\text { Lactobacillus } \\
\text { buchneri }\end{array}$ & $\begin{array}{l}\text { Média } \\
\text { Mean }\end{array}$ \\
\hline $\begin{array}{l}\text { Controle } \\
\text { Control }\end{array}$ & 5,9 & 5,6 & 5,7 & $5,8 b$ & $3,7 \mathrm{Ac}$ & $3,5 \mathrm{Bc}$ & $3,4 \mathrm{Bb}$ & $3,6 c$ \\
\hline $\begin{array}{l}\text { Benzoato } \\
\text { Benzoate }\end{array}$ & 6,0 & 5,7 & 5,7 & $5,8 b$ & $3,7 \mathrm{Ac}$ & $3,6 \mathrm{Ac}$ & $3,5 \mathrm{Bb}$ & $3,6 \mathrm{c}$ \\
\hline $\begin{array}{l}\mathrm{NaOH} \\
\text { Média }\end{array}$ & $\begin{array}{l}11,7 \\
7,3 \mathrm{~A}\end{array}$ & $\begin{array}{l}11,6 \\
7,2 \mathrm{~B}\end{array}$ & $\begin{array}{l}11,6 \\
7,2 \mathrm{~B}\end{array}$ & $\begin{array}{r}11,6 \mathrm{a} \\
7,2\end{array}$ & $\begin{array}{r}4,6 \mathrm{Aa} \\
4,1 \mathrm{~A}\end{array}$ & $\begin{array}{r}4,6 \mathrm{Aa} \\
4,0 \mathrm{~B}\end{array}$ & $\begin{array}{r}4,5 \mathrm{Ba} \\
4,0 \mathrm{~B}\end{array}$ & $\begin{array}{r}4,6 a \\
4,0\end{array}$ \\
\hline $\begin{array}{l}\text { Mean } \\
\text { CV (\%) }\end{array}$ & & & & 1,71 & & & & 1,40 \\
\hline
\end{tabular}

Médias seguidas da mesma letra, maiúscula na linha e minúscula na coluna, não diferem $(P>0,05)$ estatisticamente pelo teste Tukey.

${ }^{1} 1,5 \%$ de uréia; $0,1 \%$ de benzoato de sódio e 1\% de hidróxido de sódio em relação à matéria verde.

Means followed by the same small letter within a column or capital letter in a row are similar $(P>0.05)$ by Tukey test.

${ }^{1}$ Urea $1.5 \%$; sodium benzoate $0.1 \%$ and sodium hydroxide $1.0 \%$ on the wet basis.

(1998) utilizaram Propionibacterium na ensilagem de milho e não notaram efeito sobre a contagem de leveduras durante o período fermentativo, uma vez que o $\mathrm{pH}$ das silagens com três dias de fermentação foi inferior a 4,2 e após 90 dias foi 3,75. Provavelmente, ao ensilar a cana-de-açúcar sem aditivo alcalinizante, o pH reduziu rapidamente a valores inferiores a 4,0. Entretanto, quando a cana-de-açúcar foi ensilada com $\mathrm{NaOH}$, o pH não sofreu redução a níveis inferiores, o que possibilitou maior tempo para ação das bactérias acidopropiônicas.

A associação de L. buchneri com benzoato ou com $\mathrm{NaOH}$ propiciou baixas perdas por gases $(\mathrm{P}<0,05)$. O efeito das associações do L. buchneri com $\mathrm{NaOH}$ ou com benzoato de sódio têm explicações diferentes. Woolford (1975) considera o benzoato de sódio inibidor de bactérias heterofermentativas, no entanto, nesse estudo observou-se efeito sinérgico da atuação entre o L. buchneri e o benzoato. Ressalta-se que esse efeito pode ter sido um somatório e não propriamente um estímulo do benzoato na atuação do L. buchneri. Com a associação de $\mathrm{NaOH}$ e L. buchneri, é possível que a manutenção do $\mathrm{pH}$ em valores mais altos durante a fermentação tenha estimulado o crescimento de L. buchneri e aumentado a síntese de ácido acético, que tem como função nessas silagens inibir o crescimento de leveduras, o que é importante, pois as leveduras são as principais responsáveis pela produção de $\mathrm{CO}_{2}$ durante a fermentação dos carboidratos solúveis a etanol.

Na associação dos inoculantes $P$. acidipropionici + L. plantarum e L. buchneri com $\mathrm{NaOH}$, outro efeito pode ter propiciado a redução da perda por gases: a inclusão de substâncias alcalinas, que estimula a proliferação de bac- térias homofermentativas, que aumentam a produção de ácido lático, especialmente na ensilagem da cana-de-açúcar (Nieblas et al., 1982). O ácido lático é considerado substrato tanto para o P. acidipropionici quanto para o L. buchneri produzirem ácido propiônico e ácido acético, respectivamente (McDonald et al., 1991; Oude Elferink et al., 2001). No caso do L. buchneri, além da produção de ácido acético, ocorre síntese de 1,2-propanodiol, que também é um composto com efeito inibitório sobre o crescimento de leveduras (Oude Elferink et al., 2001).

A produção de efluente pelas silagens de cana-deaçúcar (Tabela 3), exceto as tratadas com $\mathrm{NaOH}$, foi alta em comparação aos resultados observados na literatura. Schmidt et al. (2004) observaram produções de efluente de 30,4 a 42,5 kg/t MV, enquanto, neste estudo, a média foi de $58,1 \mathrm{~kg} / \mathrm{t} \mathrm{MV}$. Alguns fatos podem estar relacionados a essa superestimativa da produção de efluentes, o primeiro relacionado a picagem do material, pois, apesar de não ter sido quantificado o tamanho das partículas, visualmente observou-se dilaceração de muitas partículas, produzindo fragmentos muito pequenos. Outra explicação seria o processo de ensilagem em silos experimentais de PVC, pois os bastões de ferro utilizados na compactação da forragem apresentavam diâmetro próximo ao dos silos, o que propiciou compactação sobre toda a superfície do silo, não permitindo movimentação da forragem. Essa forma de compactação pode ter provocado maior dilaceramento das partículas ensiladas e aumentado a produção de efluente.

Independentemente do aditivo químico, as silagens inoculadas com L. buchneri apresentaram maior recuperação da MS $(\mathrm{P}<0,05)$. Ressalta-se que as silagens tratadas com $\mathrm{NaOH}$ e inoculadas com P. acidipropionici 
+ L. plantarum e L. buchneri apresentaram ainda maior recuperação da MS em comparação às demais tratadas com aditivos.

Segundo Pedroso et al. (2005), a recuperação da MS tem alta correlação com a perda por gases (98,4\%). Portanto, é possível associar as perdas por gases à recuperação da MS dessas silagens, pois o maior redutor da recuperação da MS na ensilagem de cana-de-açúcar é a produção de $\mathrm{CO}_{2}$ por leveduras durante a fermentação dos carboidratos a etanol. De acordo com McDonald et al. (1991), a fermentação por leveduras gera perdas de $48,9 \%$ de MS e de $0,2 \%$ de energia, portanto, a recuperação da MS nas silagens tratadas com $\mathrm{NaOH}$ sem inoculação deveria ser superior à das demais silagens não inoculadas. No entanto, este fato não ocorreu, pois estas silagens não diferiram daquelas tratadas apenas com uréia e benzoato. Uma possível explicação seria a variação dos teores de MS (Tabela 4). O cálculo da perda por gases consiste na diferença de peso do silo, considerando a matéria verde ensilada e após a abertura. A produção de efluente é medida pelo aumento do peso do conjunto silo, areia, tela e náilon, no entanto, essas duas medidas não incluem a transformação de substratos da forma sólida para líquida e que não lixiviam até o fundo do silo. A variação no teor de MS das silagens tratadas apenas com $\mathrm{NaOH}$ não diferiu $(\mathrm{P}>0,05)$ em relação às silagens controle e tratadas apenas com uréia, indicando decréscimo acentuado no teor de MS, que afetou a recuperação da MS.

As determinações dos teores de MS antes da ensilagem (Tabela 5) podem ser consideradas ideais para ensilagem da cana-de-açúcar. As variações entre os teores de MS antes da ensilagem foram resultado do tempo do corte até a confecção do silo.

Após a abertura, as diferenças entre os teores de MS das silagens foram provenientes das perdas de MS durante a fermentação. Alli et al. (1983) avaliaram o perfil de fermentação de silagens de cana-de-açúcar tratadas ou não com hidróxido de amônia e observaram redução de 4 e 1 unidades percentuais de MS, respectivamente, nas silagens controle e tratadas durante 42 dias de fermentação. Evangelista et al. (2003) verificaram redução de 36,0 para 25,3\% de MS em dez dias de fermentação. Nos dois trabalhos, atribui-se a redução da MS ao consumo de carboidratos solúveis durante a fermentação. Neste estudo, os maiores teores de MS foram encontrados nas silagens com maiores recuperações da MS, o que reflete a importância de se avaliar a variação entre os teores de MS antes da ensilagem e após a abertura.

As silagens inoculadas com $L$. buchneri mantiveram, independentemente do aditivo químico utilizado, os menores valores de $\mathrm{pH}$ (Tabela 6) e foram acompanhadas das silagens tratadas com Propionibacterium acidipropionici + Lactobacillus plantarum e, por último, pelas silagens do grupo controle, que apresentaram os maiores valores de $\mathrm{pH}$ $(\mathrm{P}<0,05)$. Independentemente da inoculação, os menores valores foram observados nas silagens tratadas com benzoato e os maiores nas silagens tratadas com uréia $(\mathrm{P}<0,05)$.

Além do valor absoluto do pH, é necessária a avaliação da variação do $\mathrm{pH}$, pois a interpretação simplista dos valores de $\mathrm{pH}$ após a exposição aeróbia pode ocasionar considerações errôneas. Assim, as silagens tratadas com

Tabela 3 - Perdas por gases (\% da MS ensilada) e por efluentes ( $\mathrm{kg} / \mathrm{t} \mathrm{MV} \mathrm{ensilada)} \mathrm{em} \mathrm{silagens} \mathrm{de} \mathrm{cana-de-açúcar} \mathrm{tratadas} \mathrm{com} \mathrm{aditivos}$ químicos e bacterianos

Table 3 - Sugar cane silage gas losses (GL) in relation to the ensiled DM and effluent losses in relation to the ensiled wet matter, in function of the chemical and bacterial additive association

\begin{tabular}{|c|c|c|c|c|c|c|c|c|}
\hline \multirow[t]{2}{*}{$\begin{array}{l}\text { Tratamen } \\
\text { Treatment }\end{array}$} & \multirow[b]{2}{*}{$\begin{array}{c}\text { Controle } \\
\text { Control }\end{array}$} & \multicolumn{3}{|c|}{$\begin{array}{c}\text { Perdas por gases (\% da MS) } \\
\text { Gas losses (\% DM) }\end{array}$} & \multicolumn{4}{|c|}{$\begin{array}{c}\text { Perdas por efluente (kg/t MV) } \\
\text { Effluent losses ( } \mathrm{kg} / \mathrm{t} \text { forage) }\end{array}$} \\
\hline & & $\begin{array}{c}\text { Propionibacterium } \\
\text { acidipropionici }+ \\
\text { Lactobacillus plantarum }\end{array}$ & $\begin{array}{l}\text { Lactobacillus } \\
\text { buchneri }\end{array}$ & $\begin{array}{l}\text { Média } \\
\text { Mean }\end{array}$ & $\begin{array}{c}\text { Controle } \\
\text { Control }\end{array}$ & $\begin{array}{c}\text { Propionibacterium } \\
\text { acidipropionici }+ \\
\text { Lactobacillus plantarum }\end{array}$ & $\begin{array}{l}\text { Lactobacillus } \\
\text { buchneri }\end{array}$ & $\begin{array}{l}\text { Média } \\
\text { Mean }\end{array}$ \\
\hline $\begin{array}{l}\text { Controle } \\
\text { Control }\end{array}$ & $15,9 \mathrm{Ba}$ & 19,9Аа & $13,2 \mathrm{Ca}$ & $16,4 a$ & $76,2 \mathrm{ABa}$ & $84,9 \mathrm{Aa}$ & $66,5 \mathrm{Bb}$ & $75,9 a b$ \\
\hline $\begin{array}{l}\text { Benzoato } \\
\text { Benzoate }\end{array}$ & $11,2 \mathrm{Abc}$ & $12,6 \mathrm{Ab}$ & $7,3 \mathrm{Bb}$ & $10,4 \mathrm{c}$ & $63,0 \mathrm{Cab}$ & $98,4 \mathrm{Aa}$ & $82,2 \mathrm{Ba}$ & $81,2 \mathrm{a}$ \\
\hline $\mathrm{NaOH}$ & $9,6 \mathrm{Ac}$ & $6,4 \mathrm{Bc}$ & $6,2 \mathrm{Bb}$ & $7,4 d$ & 3,2Ac & $5,8 \mathrm{Ab}$ & $2,2 \mathrm{Ac}$ & $3,7 c$ \\
\hline $\begin{array}{l}\text { Média } \\
\text { Mean }\end{array}$ & $12,5 \mathrm{~A}$ & $13,2 \mathrm{~A}$ & 9,7B & 11,8 & $49,7 \mathrm{~B}$ & $68,2 \mathrm{~A}$ & $56,5 \mathrm{~B}$ & 58,1 \\
\hline CV (\%) & & & & 11,08 & & & & 11,93 \\
\hline
\end{tabular}

Médias seguidas da mesma letra, maiúscula na linha e minúscula na coluna, não diferem $(P>0,05)$ estatisticamente pelo teste Tukey.

1 1,5\% de uréia; $0,1 \%$ de benzoato de sódio e $1 \%$ de hidróxido de sódio em relação à matéria verde.

Means followed by the same small letter within a column or capital letter in a row are similar $(P>0.05)$ by Tukey test.

1 Urea $1.5 \%$; sodium benzoate $0.1 \%$ and sodium hydroxide $1.0 \%$ on the wet basis. 
Tabela 4 - Recuperação da MS (\% MS ensilada) e variação dos teores de MS (diferença em módulo entre a \% MS na ensilagem e a \% MS na abertura do silo) de silagens de cana-de-açúcar tratadas com aditivos químicos e bacterianos

Table 4 - Sugar cane silage DM recovery (\%) in relation to the ensiled forage, DM changes calculated by the difference of the sugar cane DM concentration on the ensilage and after silos opening, in function of the chemical and bacterial additive association

\begin{tabular}{|c|c|c|c|c|c|c|c|c|}
\hline \multirow[t]{2}{*}{$\begin{array}{l}\text { Tratament } \\
\text { Treatment }\end{array}$} & \multicolumn{4}{|c|}{$\begin{array}{c}\text { Recuperação da MS (\%) } \\
\text { DM recovery (\%) }\end{array}$} & \multicolumn{4}{|c|}{$\begin{array}{c}\text { Variação nos teores de MS } \\
\text { DM change }\end{array}$} \\
\hline & $\begin{array}{c}\text { Controle } \\
\text { Control }\end{array}$ & $\begin{array}{c}\text { Propionibacterium } \\
\text { acidipropionici }+ \\
\text { Lactobacillus plantarum }\end{array}$ & $\begin{array}{l}\text { Lactobacillus } \\
\text { buchneri }\end{array}$ & $\begin{array}{l}\text { Média } \\
\text { Mean }\end{array}$ & $\begin{array}{l}\text { Controle } \\
\text { Control }\end{array}$ & $\begin{array}{c}\text { Propionibacterium } \\
\text { acidipropionici }+ \\
\text { Lactobacillus plantarum }\end{array}$ & $\begin{array}{l}\text { Lactobacillus } \\
\text { buchneri }\end{array}$ & $\begin{array}{l}\text { Média } \\
\text { Mean }\end{array}$ \\
\hline $\begin{array}{l}\text { Controle } \\
\text { Control }\end{array}$ & $67,5 \mathrm{Bb}$ & $66,4 \mathrm{Bc}$ & $80,8 \mathrm{Ac}$ & $71,6 \mathrm{~d}$ & 7,8Аa & 7,6Аа & $3,1 \mathrm{Ba}$ & $6,2 \mathrm{a}$ \\
\hline $\begin{array}{l}\text { Uréia } \\
\text { Urea }\end{array}$ & $72,8 \mathrm{Ba}$ & $75,0 \mathrm{Bb}$ & 79,7Ac & $75,8 c$ & 6,7Aab & $4,7 \mathrm{Bb}$ & $3,4 \mathrm{Ca}$ & $4,9 b$ \\
\hline $\begin{array}{l}\text { Benzoato } \\
\text { Benzoate }\end{array}$ & $74,8 \mathrm{Ba}$ & $74,8 \mathrm{Bb}$ & $87,2 \mathrm{Ab}$ & $78,9 b$ & $5,9 \mathrm{Ab}$ & $4,5 \mathrm{Bb}$ & $0,8 \mathrm{Cb}$ & $3,7 c$ \\
\hline $\begin{array}{l}\mathrm{NaOH} \\
\text { Média } \\
\text { Mean } \\
\mathrm{CV}(\%)\end{array}$ & $\begin{array}{r}76,1 \mathrm{Ca} \\
72,8 \mathrm{C}\end{array}$ & $\begin{array}{r}86,5 \mathrm{Ba} \\
75,7 \mathrm{~B}\end{array}$ & $\begin{array}{r}93,7 \mathrm{Aa} \\
85,3 \mathrm{~A}\end{array}$ & $\begin{array}{r}85,4 a \\
77,9\end{array}$ & $\begin{array}{r}7,7 \mathrm{Aa} \\
7,0 \mathrm{~A}\end{array}$ & $\begin{array}{r}3,9 \mathrm{Bb} \\
5,2 \mathrm{~B}\end{array}$ & $\begin{array}{r}1,4 \mathrm{Cb} \\
2,2 \mathrm{C}\end{array}$ & $\begin{array}{r}4,4 \mathrm{bc} \\
4,8\end{array}$ \\
\hline
\end{tabular}

Médias seguidas da mesma letra, maiúscula na linha e minúscula na coluna, não diferem $(P>0,05)$ estatisticamente pelo teste Tukey.

${ }_{1}^{1}, 5 \%$ de uréia; $0,1 \%$ de benzoato de sódio e $1 \%$ de hidróxido de sódio em relação à matéria verde.

Means followed by the same small letter within a column or capital letter in a row are similar $(P>0.05)$ by Tukey test.

1 Urea $1.5 \%$; sodium benzoate $0.1 \%$ and sodium hydroxide $1.0 \%$ on the wet basis.

Tabela 5 - Teores de MS (\%), antes da ensilagem e após abertura dos silos, de silagens de cana-de-açúcar tratadas com aditivos químicos e bacterianos

Table 5 - Sugar cane DM concentration (DM \%) before ensilage and after silos opening in function of the chemical and bacterial additive association

\begin{tabular}{|c|c|c|c|c|c|c|c|c|}
\hline \multirow[t]{2}{*}{$\begin{array}{l}\text { Tratamen } \\
\text { Treatment }\end{array}$} & \multicolumn{4}{|c|}{$\begin{array}{l}\text { Ensilagem } \\
\text { Ensilage }\end{array}$} & \multicolumn{4}{|c|}{$\begin{array}{c}\text { Abertura } \\
\text { Silos-opening }\end{array}$} \\
\hline & $\begin{array}{c}\text { Controle } \\
\text { Control }\end{array}$ & $\begin{array}{c}\text { Propionibacterium } \\
\text { acidipropionici }+ \\
\text { Lactobacillus plantarum }\end{array}$ & $\begin{array}{l}\text { Lactobacillus } \\
\text { buchneri }\end{array}$ & $\begin{array}{l}\text { Média } \\
\text { Mean }\end{array}$ & $\begin{array}{c}\text { Controle } \\
\text { Control }\end{array}$ & $\begin{array}{c}\text { Propionibacterium } \\
\text { acidipropionici }+ \\
\text { Lactobacillus plantarum }\end{array}$ & $\begin{array}{l}\text { Lactobacillus } \\
\text { buchneri }\end{array}$ & $\begin{array}{l}\text { Média } \\
\text { Mean }\end{array}$ \\
\hline $\begin{array}{l}\text { Controle } \\
\text { Control }\end{array}$ & $35,2 \mathrm{Ab}$ & $35,6 \mathrm{Aa}$ & $35,1 \mathrm{Aa}$ & $35,3 a b$ & $27,4 \mathrm{Bb}$ & $28,0 \mathrm{Bd}$ & $31,9 \mathrm{Ac}$ & $29,1 \mathrm{c}$ \\
\hline $\begin{array}{l}\text { Benzoato } \\
\text { Benzoate }\end{array}$ & $35,2 \mathrm{Ab}$ & $35,1 \mathrm{Aab}$ & $35,5 \mathrm{Aa}$ & $35,3 a b$ & $29,4 \mathrm{Ca}$ & $30,6 \mathrm{Bb}$ & $34,7 \mathrm{Aa}$ & $31,6 a$ \\
\hline $\mathrm{NaOH}$ & 36,8Аa & $36,2 \mathrm{Aa}$ & 34,9Bа & $35,9 a$ & $29,1 \mathrm{Ca}$ & $32,2 \mathrm{Ba}$ & $33,5 \mathrm{Ab}$ & $31,6 a$ \\
\hline $\begin{array}{l}\text { Média } \\
\text { Mean } \\
\text { CV (\%) }\end{array}$ & 35,7A & $35,2 \mathrm{AB}$ & $35,0 \mathrm{~B}$ & 35,3 & $28,7 \mathrm{C}$ & $30,1 \mathrm{~B}$ & $32,8 \mathrm{~A}$ & 30,5 \\
\hline
\end{tabular}

Médias seguidas da mesma letra, maiúscula na linha e minúscula na coluna, não diferem $(P>0,05)$ estatisticamente pelo teste Tukey.

${ }^{1} 1,5 \%$ de uréia; $0,1 \%$ de benzoato de sódio e $1 \%$ de hidróxido de sódio em relação à matéria verde.

Means followed by the same small letter within a column or capital letter in a row are similar $(P>0.05)$ by Tukey test.

1 Urea $1.5 \%$; sodium benzoate $0.1 \%$ and sodium hydroxide $1.0 \%$ on the wet basis.

$\mathrm{NaOH}$, que, na avaliação dos valores de pH tiveram média geral de 5,9 (Tabela 6), estatisticamente superior à média das silagens controle $(4,6)$, seriam prejudicadas, uma vez que na avaliação da $\mathrm{VpH}$ não houve diferença $(\mathrm{P}>0,05)$ entre as médias, pois o pH após a abertura das silagens tratadas com $\mathrm{NaOH}$ foi superior ao das demais (Tabela 2).

As menores variações no $\mathrm{pH}$ foram observadas nas silagens tratadas com benzoato, que, segundo Woolford (1975), tem efeito inibitório sobre o metabolismo de leveduras. Warth (1988) avaliou o efeito do benzoato sobre o metabolismo de várias espécies de leveduras e constatou que o efeito desse aditivo diferiu conforme a espécie. Portanto, pode-se inferir que as espécies que atuam durante a exposição aeróbia foram mais sensíveis ao benzoato que as espécies fermentativas. L. buchneri também foi eficiente em controlar a variação do $\mathrm{pH}$, pois tem efeito inibitório sobre o metabolismo de leveduras e fungos filamentosos, em decorrência da produção de ácido acético (Ranjit \& Kung Jr., 2000). Esse efeito pode ser constatado neste estudo pela manutenção do $\mathrm{pH}$, que seria elevado se houvesse consumo de ácido lático por leveduras e mofos. 
Os teores de MS após cinco dias de exposição aeróbia não diferiram estatisticamente $(\mathrm{P}>0,05)$ entre aditivos químicos (Tabela 7), mas foram influenciados pelos inoculantes (Propionibacterium acidipropionici + Lactobacillus plantarum e Lactobacillus buchneri) e as silagens controle. A elevação dos teores de MS durante a exposição aeróbia é ocasionada pela perda de água para o ambiente.

A recuperação de MS após cinco dias de exposição aeróbia não foi influenciada $(\mathrm{P}>0,05)$ pela inoculação, independentemente do aditivo químico, no entanto, entre as silagens tratadas com aditivos químicos, os valores foram maiores nas silagens controle e naquelas tratadas com benzoato e uréia $(\mathrm{P}<0,05)$.

As silagens inoculadas apenas com Propionibacterium acidipropionici + Lactobacillus plantarum apresentaram baixa recuperação da MS durante a fermentação $(97,4 \%)$ (Tabelas 4 e 7$)$, o que permite inferir que provavelmente essas silagens passaram por intenso processo de fermentação alcoólica, transformando-se em silagens com baixo nível de substrato para atuação microbiana durante a exposição aeróbia.

Não houve diferença entre os aditivos químicos quanto à estabilidade aeróbia $(\mathrm{P}>0,05)$, no entanto, as silagens inoculadas com Propionibacterium acidipropionici + Lactobacillus plantarum e Lactobacillus buchneri foram superiores $(\mathrm{P}<0,05)$ às silagens controle (Tabela 8$)$.

O inoculante Propionibacterium acidipropionici + Lactobacillus plantarum apresenta em sua composição a bactéria Propionibacterium acidipropionici e o Lactobacillus plantarum. Segundo Dawson et al. (1998), a inclusão de $P$. acidipropionici foi eficiente em elevar a estabilidade aeróbia de silagens de grãos úmidos de milho e em diminuir as populações de leveduras, mofos e bactérias aeróbias durante cinco dias de exposição ao ar. Fylia et al. (2004) avaliaram a inoculação de $P$. acidipropionici e L. plantarum, associados ou não, na ensilagem de milho, sorgo e trigo e concluíram que o $P$. acidipropionici foi eficiente em controlar as populações de leveduras e mofos e a produção de $\mathrm{CO}_{2}$ durante a exposição aeróbia, no entanto, a associação dos dois microrganismos não proporcionou resultados significativamente diferentes das silagens controle. Em ambos os trabalhos, os autores atribuíram o efeito do $P$. acidipropionici sobre a estabilidade em aerobiose das silagens ao fato de esse microrganismo ser produtor de ácido propiônico, que, segundo Moon (1983), tem efeito inibitório sobre o metabolismo de leveduras, principais microrganismos deterioradores de silagens em exposição aeróbia (McDonald et al., 1991).

O L. buchneri tem sido amplamente estudado como microrganismo promotor de elevação da estabilidade pósabertura. Em todos os trabalhos analisados, existe consenso sobre a inibição de leveduras e mofos pela ação do ácido acético e 1,2 propanodiol produzidos pelo $L$. buchneri (Oude Elferink et al., 2001). Os fungos (leveduras e mofos) são os microrganismos que mais provocam elevação da temperatura da silagem no período pós-abertura.

Tabela 6 - Valores de pH após cinco dias de exposição aeróbia e variação do pH (diferença em módulo entre o pH após aeração e pH após a abertura dos silos) de silagens de cana-de-açúcar tratadas com aditivos químicos e bacterianos

Table 6 - $\quad$ Sugar cane silage $\mathrm{pH}$ values evaluated five days after air exposure, $\mathrm{pH}$ changes calculated by the difference of the values observed after air exposure and silos opening in function of the chemical and bacterial additive association

\begin{tabular}{|c|c|c|c|c|c|c|c|c|}
\hline \multirow[t]{2}{*}{$\begin{array}{l}\text { Tratamen } \\
\text { Treatment }\end{array}$} & \multicolumn{4}{|l|}{$0^{1}$} & \multicolumn{4}{|c|}{$\begin{array}{c}\text { Variação do } \mathrm{pH} \\
\text { pH change }\end{array}$} \\
\hline & $\begin{array}{l}\text { Controle } \\
\text { Control }\end{array}$ & $\begin{array}{c}\text { Propionibacterium } \\
\text { acidipropionici }+ \\
\text { Lactobacillus plantarum }\end{array}$ & $\begin{array}{l}\text { Lactobacillus } \\
\text { buchneri }\end{array}$ & $\begin{array}{l}\text { Média } \\
\text { Mean }\end{array}$ & $\begin{array}{c}\text { Controle } \\
\text { Control }\end{array}$ & $\begin{array}{c}\text { Propionibacterium } \\
\text { acidipropionici }+ \\
\text { Lactobacillus plantarum }\end{array}$ & $\begin{array}{l}\text { Lactobacillus } \\
\text { buchneri }\end{array}$ & $\begin{array}{l}\text { Média } \\
\text { Mean }\end{array}$ \\
\hline $\begin{array}{l}\text { Controle } \\
\text { Control }\end{array}$ & $6,1 \mathrm{Ab}$ & $3,9 \mathrm{Bb}$ & $3,7 \mathrm{Bb}$ & $4,6 c$ & $2,4 \mathrm{Ab}$ & $0,4 \mathrm{Bc}$ & $0,2 \mathrm{Bb}$ & $1,0 \mathrm{~b}$ \\
\hline $\begin{array}{l}\text { Benzoato } \\
\text { Benzoate }\end{array}$ & $3,7 \mathrm{Ac}$ & $3,6 \mathrm{Ab}$ & $3,6 \mathrm{Ab}$ & $3,6 \mathrm{~d}$ & $0,1 \mathrm{Ad}$ & $0,1 \mathrm{Ac}$ & $0,1 \mathrm{Ab}$ & $0,1 \mathrm{c}$ \\
\hline $\begin{array}{l}\mathrm{NaOH} \\
\text { Média }\end{array}$ & $\begin{array}{r}6,0 \mathrm{Ab} \\
6,0 \mathrm{~A}\end{array}$ & $\begin{array}{r}6,2 \mathrm{Aa} \\
5,1 \mathrm{~B}\end{array}$ & $\begin{array}{r}5,6 \mathrm{Aa} \\
4,4 \mathrm{C}\end{array}$ & $\begin{array}{r}5,9 b \\
5,2\end{array}$ & $\begin{array}{r}1,3 \mathrm{Ac} \\
2,0 \mathrm{~A}\end{array}$ & $\begin{array}{r}1,6 \mathrm{Ab} \\
1,1 \mathrm{~B}\end{array}$ & $\begin{array}{r}1,1 \mathrm{Aa} \\
0,4 \mathrm{C}\end{array}$ & $\begin{array}{r}1,3 \mathrm{~b} \\
1,2\end{array}$ \\
\hline $\begin{array}{l}\text { Mean } \\
\text { CV (\%) }\end{array}$ & & & & 6,60 & & & & 28,37 \\
\hline
\end{tabular}

Médias seguidas da mesma letra, maiúscula na linha e minúscula na coluna, não diferem $(P>0,05)$ estatisticamente pelo teste Tukey.

1 1,5\% de uréia; $0,1 \%$ de benzoato de sódio e $1 \%$ de hidróxido de sódio em relação à matéria verde.

Means followed by the same small letter within a column or capital letter in a row are similar $(P>0.05)$ by Tukey test.

1 Urea $1.5 \%$; sodium benzoate $0.1 \%$ and sodium hydroxide $1.0 \%$ on the wet basis. 
Tabela 7 - Teores de MS (\%) e recuperação da MS (\% MS na abertura dos silos) após cinco dias de exposição aeróbia de silagens de cana-de-açúcar tratadas com aditivos químicos e bacterianos

Table 7 - Sugar cane silage DM concentration (\%), DM recovery in relation to the ensiled dry matter (DMR) observed five days after air exposure, in function of the chemical and bacterial additive association

\begin{tabular}{|c|c|c|c|c|c|c|c|c|}
\hline \multicolumn{2}{|c|}{$\begin{array}{l}\text { Tratamento }{ }^{1} \\
\text { Treatment }\end{array}$} & \multicolumn{3}{|c|}{$\begin{array}{l}\text { MS (\%) } \\
D M(\%)\end{array}$} & \multicolumn{4}{|c|}{$\begin{array}{c}\text { Recuperação da MS (\%) } \\
\text { DM recovery (\%) }\end{array}$} \\
\hline & $\begin{array}{l}\text { Controle } \\
\text { Control }\end{array}$ & $\begin{array}{c}\text { Propionibacterium } \\
\text { acidipropionici }+ \\
\text { Lactobacillus plantarum }\end{array}$ & $\begin{array}{l}\text { Lactobacillus } \\
\text { buchneri }\end{array}$ & $\begin{array}{l}\text { Média } \\
\text { Mean }\end{array}$ & $\begin{array}{l}\text { Controle } \\
\text { Control }\end{array}$ & $\begin{array}{c}\text { Propionibacterium } \\
\text { acidipropionici }+ \\
\text { Lactobacillus plantarum }\end{array}$ & $\begin{array}{l}\text { Lactobacillus } \\
\text { buchneri }\end{array}$ & $\begin{array}{l}\text { Média } \\
\text { Mean }\end{array}$ \\
\hline $\begin{array}{l}\text { Controle } \\
\text { Control }\end{array}$ & 39,3 & 37,6 & 37,1 & $38,0 \mathrm{a}$ & $96,2 \mathrm{Aa}$ & $97,4 \mathrm{Aa}$ & $92,7 \mathrm{Aab}$ & $95,4 a$ \\
\hline $\begin{array}{l}\text { Benzoato } \\
\text { Benzoate }\end{array}$ & 40,4 & 38,4 & 41,6 & $40,1 \mathrm{a}$ & $95,0 \mathrm{Aa}$ & $96,8 \mathrm{Aa}$ & $94,2 \mathrm{Aa}$ & $95,3 a$ \\
\hline $\mathrm{NaOH}$ & 44,4 & 35,5 & 36,6 & $38,8 a$ & $93,9 \mathrm{Aa}$ & $89,8 \mathrm{Ab}$ & $90,9 \mathrm{Ab}$ & $91,5 b$ \\
\hline $\begin{array}{l}\text { Média } \\
\text { Mean }\end{array}$ & $42,1 \mathrm{~A}$ & $37,0 \mathrm{~B}$ & $37,8 \mathrm{~B}$ & 39,0 & $94,0 \mathrm{~A}$ & $94,4 \mathrm{~A}$ & 93,7A & 94,0 \\
\hline CV (\%) & & & & 9,08 & & & & 2,65 \\
\hline
\end{tabular}

Médias seguidas da mesma letra, maiúscula na linha e minúscula na coluna, não diferem $(P>0,05)$ estatisticamente pelo teste Tukey.

${ }_{1} 1,5 \%$ de uréia; $0,1 \%$ de benzoato de sódio e $1 \%$ de hidróxido de sódio em relação à matéria verde.

Means followed by the same small letter within a column or capital letter in a row are similar $(P>0.05)$ by Tukey test.

1 Urea $1.5 \%$; sodium benzoate $0.1 \%$ and sodium hydroxide $1.0 \%$ on the wet basis.

Tabela 8 - Estabilidade aeróbia (h) e teores de nitrogênio amoniacal em relação ao nitrogênio total na $\mathrm{MS}\left(\mathrm{N}-\mathrm{NH}_{3}\right)$ após cinco dias de exposição aeróbia de silagens de cana-de-açúcar tratadas com aditivos químicos e bacterianos

Table 8 - Sugar cane silage aerobic stability (h), ammonia nitrogen in relation to total $\mathrm{N}\left(\mathrm{N}_{-}-\mathrm{NH}_{3}\right)$ observed five days after air exposure in function of the chemical and bacterial additive association

\begin{tabular}{|c|c|c|c|c|c|c|c|c|}
\hline \multirow[t]{2}{*}{$\begin{array}{l}\text { Tratament } \\
\text { Treatment }\end{array}$} & \multicolumn{4}{|c|}{$\begin{array}{l}\text { Estabilidade aeróbia }(\mathrm{h}) \\
\text { Aerobic stability }(h)\end{array}$} & \multicolumn{4}{|c|}{$\begin{array}{c}\mathrm{N}-\mathrm{NH}_{3} / \mathrm{NT}(\%) \\
\mathrm{N} \text { ammonia }\left(\mathrm{N}-\mathrm{NH}_{3} / \mathrm{TN}\right)\end{array}$} \\
\hline & $\begin{array}{l}\text { Controle } \\
\text { Control }\end{array}$ & $\begin{array}{c}\text { Propionibacterium } \\
\text { acidipropionici }+ \\
\text { Lactobacillus plantarum }\end{array}$ & $\begin{array}{l}\text { Lactobacillus } \\
\text { buchneri }\end{array}$ & $\begin{array}{l}\text { Média } \\
\text { Mean }\end{array}$ & $\begin{array}{l}\text { Controle } \\
\text { Control }\end{array}$ & $\begin{array}{c}\text { Propionibacterium } \\
\text { acidipropionici }+ \\
\text { Lactobacillus plantarum }\end{array}$ & $\begin{array}{l}\text { Lactobacillus } \\
\text { buchneri }\end{array}$ & $\begin{array}{l}\text { Média } \\
\text { Mean }\end{array}$ \\
\hline $\begin{array}{l}\text { Controle } \\
\text { Control }\end{array}$ & 32,0 & 60,0 & 60,0 & $50,7 a$ & $4,2 \mathrm{Ab}$ & $2,6 \mathrm{Ab}$ & $2,8 \mathrm{Ab}$ & $3,2 b$ \\
\hline $\begin{array}{l}\text { Uréia } \\
\text { Urea }\end{array}$ & 40,0 & 60,0 & 48,0 & 49,3а & $26,0 \mathrm{Ca}$ & $37,2 \mathrm{Ba}$ & $59,2 \mathrm{Aa}$ & $40,8 a$ \\
\hline $\begin{array}{l}\text { Benzoato } \\
\text { Benzoate }\end{array}$ & 40,0 & 48,0 & 60,0 & $49,3 а$ & $2,7 \mathrm{Ab}$ & $2,8 \mathrm{Ab}$ & $3,0 \mathrm{Ab}$ & $2,8 b$ \\
\hline $\begin{array}{l}\mathrm{NaOH} \\
\text { Média }\end{array}$ & $\begin{array}{r}24,0 \\
34,0 \mathrm{~B}\end{array}$ & $\begin{array}{r}32,0 \\
50,0 \mathrm{~A}\end{array}$ & $\begin{array}{r}48,0 \\
54,0 \mathrm{~A}\end{array}$ & $\begin{array}{r}34,7 a \\
46,0\end{array}$ & $\begin{array}{r}2,1 \mathrm{Ab} \\
8,8 \mathrm{~B}\end{array}$ & $\begin{array}{l}3,1 \mathrm{Ab} \\
11,4 \mathrm{~B}\end{array}$ & $\begin{array}{l}2,5 \mathrm{Ab} \\
16,9 \mathrm{~A}\end{array}$ & $\begin{array}{l}2,6 b \\
12,4\end{array}$ \\
\hline $\begin{array}{l}\text { Mean } \\
\text { CV (\%) }\end{array}$ & & & & 29,49 & & & & 27,45 \\
\hline
\end{tabular}

Médias seguidas da mesma letra, maiúscula na linha e minúscula na coluna, não diferem $(P>0,05)$ estatisticamente pelo teste Tukey.

1 1,5\% de uréia; $0,1 \%$ de benzoato de sódio e $1 \%$ de hidróxido de sódio em relação à matéria verde.

Means followed by the same small letter within a column or capital letter in a row are similar $(P>0.05)$ by Tukey test.

1 Urea $1.5 \%$; sodium benzoate $0.1 \%$ and sodium hydroxide $1.0 \%$ on the wet basis.

De modo geral, se comparados aos obtidos no momento da abertura dos silos, os teores de $\mathrm{N}-\mathrm{NH}_{3}$ reduziram quando as silagens foram expostas à aerobiose, provavelmente em decorrência da volatilização da amônia. Vale ressaltar o possível efeito inibitório da amônia sobre leveduras e mofos (Woolford, 1984), principalmente nas silagens tratadas com uréia e inoculadas com Propionibacterium acidipropionici + Lactobacillus plantarum, pois houve redução na variação do $\mathrm{pH}(0,2$ unidades) e elevação da recuperação de MS $(97,0 \%)$ durante a exposição aeróbia.

\section{Conclusões}

A ensilagem de cana-de-açúcar requer a inclusão de algum aditivo eficaz no controle das perdas quantitativas durante a fermentação e no período pós-abertura. O tratamento da cana-de-açúcar com L. buchneri e/ou $\mathrm{NaOH}$ minimiza as perdas quantitativas durante a fermentação. A estabilidade das silagens durante a exposição aeróbia aumenta com a inclusão de benzoato de sódio, a inoculação com $L$. buchneri e a associação desses dois aditivos. 


\section{Literatuta Citada}

ALCÁNTARA, E.; AGUILERA, A.; ELLIOT, R. et al. Fermentation and utilization by lambs of sugarcane harvested fresh and ensiled with and without $\mathrm{NaOH}$. 4. Ruminal kinetics. Animal Feed Science and Technology, v.23, p.323-331, 1989.

ALLI, I.; FAIRBAIRN, R.; BAKER, B.E. et al. The effects of ammonia on the fermentation of chopped sugarcane. Animal Feed Science and Technology, v.9, p.291-299, 1983.

ALVAREZ, F.J.; PRESTON, T.R. Ammonia/molasses and urea/ molasses as additives for ensiled sugar cane. Tropical Animal Production, v.1, p.98-104, 1976.

BERNARDES, T.F.; REIS, R.A.; SIQUEIRA, G.R. et al. Avaliação da queima e da adição de milho desintegrado com palha e sabugo na ensilagem de cana-de-açúcar. Revista Brasileira de Zootecnia, v.36, p.269-275, 2007.

CHANEY, A.L.; MARBACH, E.P. Modified reagents for determination of urea and ammonia. Clinical Chemistry, v.8, p.130-137, 1962.

DAWSON, T.E.; RUST, S.R.; YOKOYAMA, M.T. Improved fermentation and aerobic stability of ensiled, high moisture corn with use of Propionibacterium acidipropionici. Journal of Dairy Science, v.81, p.1015-1021, 1998.

DRIEHUIS, F.; OUDE ELFERINK, S.J.W.H.; Van WIKSELAAR, P.G. Fermentation characteristics and aerobic stability of grass silage inoculated with Lactobacillus buchneri, with or without homofermentative latic acid bacteria. Grass and Forage Science, v.56, p.330-343, 2001.

EVANGELISTA, A.R.; LIMA, J.A.; SIQUEIRA, G.R. et al. Perfil de fermentação da silagem de cana-de-açúcar (Saccharum officinarum L.). In: REUNIÃO ANUAL DA SOCIEDADE BRASILEIRA DE ZOOTECNIA, 40., 2003, Santa Maria. Anais... Santa Maria: Sociedade Brasileira de Zootecnia, 2003. (CD-ROM).

FLORES-GALARZA, R.O.; GLATZ, B.A.; BERN, C.J. et al. Preservation of high-moisture corn by microbial fermentation. Journal Food Protection, v.48, p.407-411, 1985.

FILYA, I.; SUCU, E.; KARABULUT, A. The effect of Propionibacterium acidipropionici, with or without Lactobacillus plantarum, on the fermentation and aerobic stability of wheat, sorghum and maize silages. Journal Applied Microbiology, v.97, p.818-821, 2004.

HIGGINBOTHAM, G.E.; MULLER, S.C.; BOLSEN, K.K. et al. Effects of inoculants containing propionic acid bacteria on fermentation and aerobic stability of corn silage. Journal of Dairy Science, v.81, p.2185-2192, 1998.

JOBIM, C.C.; GONÇALVES, G.D. Microbiologia de forragens conservadas. In: REIS, R.A.; BERNARDES, T.F.; SIQUEIRA, G.R. et al. (Eds.) Volumosos na produção de ruminantes: valor alimentício de forragens. Jaboticabal: Funep, 2003. p.1-26.

KUNG JR., L.; GRIEVE, D.B.; THOMAS, J.W. Added ammonia or microbial inoculant for fermentation and nitrogenous compounds of alfalfa ensiled at various percents of dry matter. Journal of Dairy Science, v.67, p.299-306, 1984.

KUNG JR., L.; STOKES, M.R.; LIN, C.J. Silage additives. In: BUXTON, D.R.; MUCK, R.E.; HARRISON, J.H. (Eds.) Silage science and technology. Madison: American Society of Agronomy, Crop Science Society of America, Soil Science Society of America, 2003. p.251-304.

LESSARD, J.R.; ERFLE, J.D.; SAUER, F.D. et al. Protein and amino acid patterns in maize ensiled with or without urea. Journal of the Science of Food and Agricultural, v.29, p.506-512, 1978.

McDONALD, P.; HENDERSON, A.R.; HERON, S.J.E. The biochemistry of silage. 2.ed. Marlow: Chalcomb Publications, 1991. 340p.

MOON, N.J. Inhibition of the growth of acid tolerant yeasts by acetate, lactate and propionate and their synergistic mixtures. Journal of Applied Bacteriology, v.55, p.453-460, 1983.
NIEBLAS, T.D.; SHIMADA, A.S.; PALACIOS, J.T. Manipulación de la fermentación en ensilaje de caña de azúcar y valor alimenticio para borregos. 3. Digestibilidad aparente. Veterinaria México, v.13, p.23-26, 1982.

NUSSIO, L.G.; SCHMIDT, P.; PEDROSO, A.F. Silagem de cana-deaçúcar In: EVANGEISTA, A.R.; REIS, S.T.; GOMIDE, E.M. (Eds.) Forragicultura e pastagens: temas em evidência sustentabilidade. Lavras: Editora Universidade Federal de Lavras, 2003. p.49-72.

OUDE ELFERINK, S.J.W.H.; KROONEMAN, J.; GOTTSCHAL, J.C. et al. Anaerobic conversion of lactic acid to acetic acid and 1,2-propanediol by Lactobacillus buchneri. Applied and Environmental Microbiology, v.67, p.125-132, 2001.

PAHLOW, G.; MUCK, R.E.; DRIEHUIS, F. et al. Microbiology of ensiling In: BUXTON, D.R.; MUCK, R.E.; HARRISON, J.H. (Eds.). Silage science and technology. Madison: American Society of Agronomy, Crop Science Society of America, Soil Science Society of America, 2003. p.31-94.

PEDROSO, A.F.; NUSSIO, L.G.; PAZIANI, S.F. et al. Fermentation and epiphytic microflora dynamics in sugar cane silage. Scientia Agricola, v.62, p.427-432, 2005.

PLAYNE, M.J., McDONALD, P. The buffering constituints of herbage and of silage. Journal of the Science of Food and Agricultural, v.17, p.264-268, 1966.

PÖLÖNEN, I.; TOIVONEN, V.; MAKELA, J. Different combinations of formic, propionic and benzoic acids in slaughter offal preservation for feeding to fur animals. Animal Feed Science Technology, v.71, p.197-202, 1998.

RANJIT, N.K.; KUNG JR., L. The effect of Lactobacillus buchneri, Lactobacillus plantarum, or a chemical preservation on fermentation and aerobic stability of corn silage. Journal of Dairy Science, v.83, p.526-535, 2000.

SCHMIDT, P.; NUSSIO, C.M.B.; RODRIGUES, A.A. et al. Produtividade, composição morfológica, digestibilidade e perdas no processo de ensilagem de duas variedades de cana-de-açúcar, com e sem adição de uréia. In: REUNIÃO ANUAL DA SOCIEDADE BRASILEIRA DE ZOOTECNIA, 41., 2004, Campo Grande. Anais... Campo Grande: Sociedade Brasileira de Zootecnia, 2004. (CD-ROM).

SILVA, D.J.; QUEIROZ, A.C. Análise de alimentos: métodos químicos e biológicos. 3.ed. Viçosa, MG: Editora UFV, 2002. 235p.

SIQUEIRA, G.R.; BERNARDES, T.F.; REIS, R.A. Instabilidade aeróbia de silagens: efeitos e possibilidades de prevenção. In: REIS, R.A.; SIQUEIRA, G.R.; BERTIPAGLIA, L.M.A. et al. (Eds.) Volumosos na produção de ruminantes. Jaboticabal: Funep, 2005. p.25-60.

SISTEMA PARA ANÁLISES ESTATÍSTICAS - ESTAT. versão 2.0 Jaboticabal: Universidade Estadual Paulista/Departamento de Ciências Exatas, 1994.

SUNDSTOL, F.; COXWORTH, E.M. Ammonia treatment. In: SUNDSTOL, F.; OWEN, E. (Eds.). Straw and other fibrous products as feed. Amsterdam: Elsevier, 1984. p.196-247.

WARTH, A.D. Effect of benzoic acid on growth yield of yeast differing in their resistance to preservatives. Applied and Environmental Microbiology, v.54, p.2091-2095, 1988.

WINTERS, A.L.; FYCHAN, R.; JONES, R. Effect of formic acid and a bacterial inoculant on the amino acid composition of grass silage and on animal performance. Grass and Forage Science, v.56, p.181-192, 2001.

WOOLFORD, M.K. The silage fermentation. New York: Marcel Dekker, 1984. 350p.

WOOLFORD, M.K. Microbiological screening of food preservatives, cold sterilants and specific antimicrobial agents as potential silage additives. Journal of the Science of Food and Agricultural, v.26, p.229-237, 1975.

Recebido: 20/10/2006 Aprovado: 26/6/2007 